\title{
Perception and production of linguistic and musical rhythm by Korean and English middle school students
}

\author{
LYDIA N. SLOBODIAN \\ University of Cambridge
}

\begin{abstract}
I examine rhythmic tendencies of Korean and Western middle school students in linguistic and abstract musical contexts using a series of speaking and clapping experiments. Results indicate a preference in both groups for beat subdivisions in small integer ratios and simple binary metric interpretations. These preferences are consistently more exaggerated in native English speaking students than in Korean students. Tempo was a significant factor in all tasks.
\end{abstract}

Submitted 2008 September 16; accepted 2008 September 24.

KEYWORDS: cross-cultural experimentation, rhythm, meter, perception, language

\section{INTRODUCTION}

RELATIONSHIPS between musical rhythm and culture, extensively acknowledged and anecdotally ubiquitous, are empirically understudied. While many perceptual rhythmic processes seem to operate on a fundamental cognitive level independent of environment, theories of universal human rhythmic experience tend to lack cross-cultural experimental support. Differences in rhythmic practices and theories in different musical cultures which have been examined from musicological, anthropological, and sociological perspectives suggest the possibility of empirically assessable cultural factors in music perception and performance.

Of the few to deal with this subject, two recent studies examined treatment of rhythmic ratios among Japanese and Western performers both in context (Ohgushi, 2002) and out of context (Sadakata et al., 2004), both showing significant differences between performers based on national and cultural backgrounds. Such rhythmic differences may relate to language patterns. Patel and Daniele used linguistic rhythmic measurement tools to directly compare English and French musical and linguistic rhythm, finding that pairwise variability of vocalic intervals correlates to durational contrastiveness in musical rhythms (Patel and Daniele, 2003; Patel et al., 2006). Huron and Ollen replicated the study with larger samples and the same results (Huron and Ollen, 2003).

The present experiment examines similarities and differences in musical and linguistic rhythmic production in participants from different backgrounds through a battery of rhythmic and linguistic tests on Korean, UK, and US middle school age students. The linguistic tests examine English and Korean in terms of vocalic, intervocalic, and syllabic variability to evaluate anecdotal reports and academic evidence that durational variability plays a less important role in pronunciation and perception of the Korean language. (Sohn, 1999; Jun, 2005). The abstract rhythmic experiments draw on previous studies of rhythmic tendencies in Western listeners, including a preference for small integer ratios in beat subdivision and binary metrical structure (e.g. Gabrielsson, 1987; Smith and Cuddy, 1989; Drake, 1993; Parncutt, 1994; Repp et al., 2005). This paper looks at the extent to which these tendencies apply to listeners from a different cultural and linguistic background.

\section{GENERAL METHOD}

Korean and Western middle school aged students participated in a series of tasks designed to test linguistic and musical rhythmic perception and performance. A speaking task measured the relative rhythms of English and Korean languages as well as the rhythmic tendencies of native English and Korean speakers, to measure tangible similarities between rhythmic performance in speaking and clapping. Many native 
speakers claim that Korean is "a language without rhythm" (as reported to author in group discussion of linguistic differences between English and Korean, Gyeongnam Department of Education, 2007). This phrase may indicate a lack of syllabic variability in Korean, which could result in lower vocalic and intervocalic nPVI scores. To measure this, participants were asked to read sentences in Korean, English, and Emakuah, an African language unfamiliar to all participants.

In the rhythmic clapping tasks, participants either repeated or clapped along to a rhythmic stimulus demonstrating 2:1 or 3:1 durational ratios. These tasks measured the extent to which the Korean and English students reduced or distorted ratios towards a perceptual ideal, such as the small integer ratios demonstrably preferred in previous Western experiments. The final clapping task evaluated ability and strategy used to identify an isochronous beat or tactus in rhythmic patterns, particularly those implying anacrusis, a device foreign to Korean traditional music (Pratt, 1987; Howard, 1991). Participants heard a repeating rhythmic pattern and were asked to find and clap the beat or tactus. Due to time and situational constraints, not every student took part in every task.

In addition, 470 Korean students and 20 teachers completed a questionnaire to evaluate Korean and Western music exposure in Korea. This included questions about listening and performance in school, domestic, and social situations. In all cases the questions were explained and discussed in both English and Korean.

\section{Participants}

134 Korean middle school students took part in this experiment. The students came from Goseong, Samsan, and Chulseong Middle Schools in Goseong County, and included 120 male and 14 female students averaging 4 years English language instruction (largely reading and rote repetition). As a reference, 10 English, and 15 American middle school students also took part. The English participants included 6 males and 4 females from the 11th/9th Scout Group in Cambridge; Americans included 6 male and 9 female students from Camp Hill Middle School in Pennsylvania, USA. All participants ranged in age from 11 to 14 years.

There were no significant differences between the responses of the American and English participants. In the analysis of results, I combine these groups and refer to them as the English group. There were no significant differences between participants in terms of age or gender.

\section{Equipment}

The experiment took the form of a computer program running on the command line with prompts in English. Students participated at their own pace, pressing "Enter" to hear each new stimulus. In the case of Korean students, a teacher or student familiar with the experiment assisted the participant until he was confident with the English prompts.

Stimuli took the form of sine waves at $440 \mathrm{~Hz}$, with an attack of $0.01 \mathrm{~s}$, decay of $0.03 \mathrm{~s}$, sustain of $0.01 \mathrm{~s}$, and release of $0.01 \mathrm{~s}$, created using artsbuilder (c. Stefan Westerfeld, <http://www.arts-project.org $>$ ). Students heard the stimuli through headphones. A microphone attached to the headset recorded spoken and clapped responses.

\section{Experimental Conditions and Constraints}

These experiments took place in the field, rather than in a laboratory. All testing sessions took place during regularly scheduled school classes or extra-curricular activities. This allowed greater numbers of participants than would otherwise have been possible, but led to less than ideal experimental conditions. The educational establishments involved requested that experiments be as short as possible to minimize the amount of class time that participants missed. In most cases, the experiment lasted no more than 7 minutes. The necessary use of clapped responses rather than tapping pads further limited the types of tasks that could be used to potentially generate useful data.

Korean testing sessions took place in an empty classroom or at a desk set up in the hallway. Ambient noise levels varied, and interruptions occurred in the form of teachers shouting, other students passing in the hallway, or bells ringing. After an initial explanation in English and Korean, the students were often left to complete the tasks on their own. 
In the UK, participants took the tests individually during an evening scout meeting, in a tool shed adjacent to the main scout hut, from which came occasional talking and construction noises. The experimenter and one other scout or assistant leader were always present during the testing sessions.

In the US, students left a regularly scheduled music class or band sectional to take part in the experiment on a laptop set up in an empty classroom or auditorium. During the band sectionals, it was sometimes possible to hear band instruments in the background. This was almost, but not entirely, inaudible through the headphones.

When a class bell interrupted a task, the task was restarted. Otherwise participants undertook each trial only once.

The noisiness of the conditions and resultant data necessitated special consideration in analyzing results, discussed below.

\section{Issues in Cross-cultural Experimentation}

A common accusation leveled at cross-cultural perception experiments such as this one is that they misrepresent real life processes by using artificial experimental conditions and stimuli and inherently Western and hence cross-culturally incommunicable concepts and vocabulary (e.g. Louhivuori, 2002). To maintain validity, experiments must as far as possible use relevant content and procedures, consider cultural context, and maintain accuracy and consistency in communication of tasks (Cole, 1996).

In this case, though the stimuli and tasks themselves are undeniably artificial, computer aided testing, computer generated sound, isolation of rhythmic from melodic aspects of music, identification of tactus, and rote repetition of stimuli are entirely consistent with both Korean and Western middle school students' experiences in educational and musical contexts.

Though every effort was made to ensure accurate and comprehensive explanation of the task instructions, including translation and demonstration, several students exhibited a misunderstanding or inability to complete the task, particularly in task 4, clapping the beat. This difficulty was shared by the Western participants in this study as well as in another study employing beat-finding tasks (London et al., 2006), which suggests that the task may be inherently and cross-culturally difficult to comprehend and perform. The differences mentioned above, including presence of experimenter, ambient noise, and translation of concepts may have led to some of the difference in variation and degree of the Western and English results. Analysis of the results of both groups independently reveals statistically significant patterns indicating a degree of validity despite less than ideal conditions.

\section{TASK 1: SPEAKING}

Rhythm in language has traditionally been defined categorically in terms of stress, syllable, and mora timing, on the basis of unit of isochronous rhythmization. Empirical study of linguistic rhythm has shown that this isochrony is not mechanically measurable, but subjective and perceptual (Beckman, 1992; Grabe and Low, 2002). Objective differences between the rhythm classes may include degrees of stress (Dauer, 1983; Beckman, 1992), or variability of vocalic and intervocalic intervals (Grabe and Low, 2002; Ramus, 2002). I attempted to assess the rhythmic differences between native Korean and English speakers using a series of linguistic measurement tools on recorded samples of speech.

\section{Method}

Participants read eight lines, three in English, three in Korean, and two in Emakuah, a language foreign to all participants, but which follows a CVC syllable structure and contains no sounds not found in both Korean and English. The lines are common phrases, matched for syllables (Figure 1). The Korean and Emakuah lines appeared in both Korean and Roman alphabets. Each participant read each line once.

It is impossible to accurately represent many English phonemes using the Korean alphabet. This is especially the case in the common misrepresentation of English consonant clusters as distinct syllables, turning "please" into "peu-li-seu". Such transliteration could affect rhythmic interpretation in pronunciation. For this reason, and because all participants were literate in English, this task used only the 


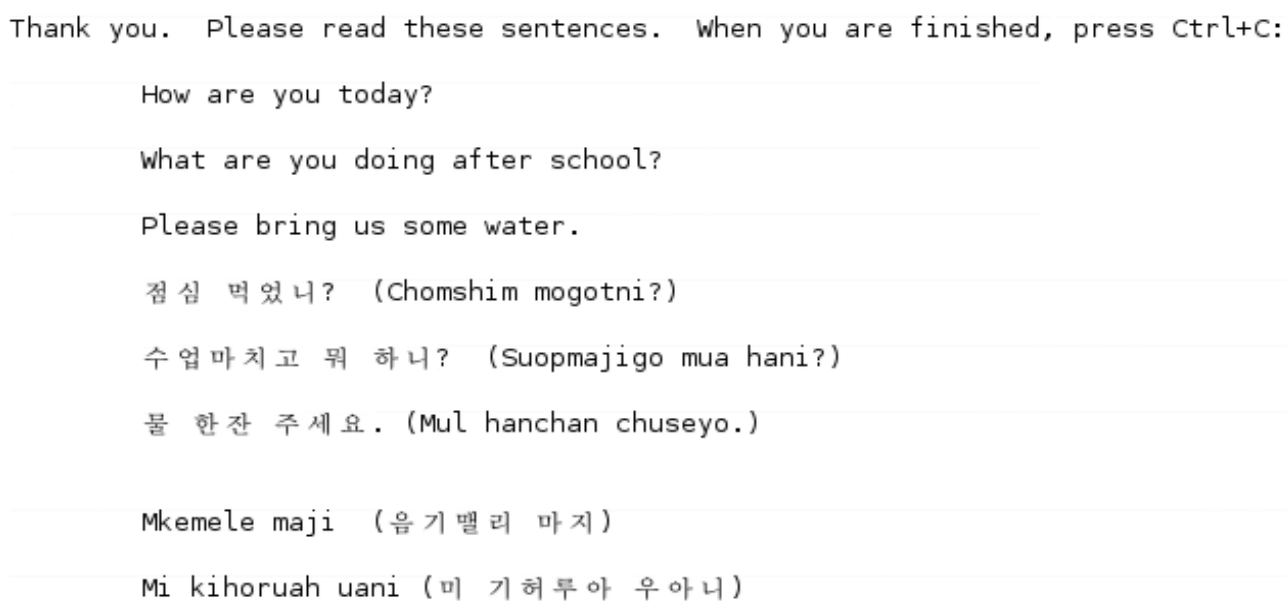

Fig. 1. Screenshot of task 1: Reading sentences

Roman alphabet for presenting the English lines. 72 Korean participants and 15 US participants took part in this task.

I analyzed the recorded speech with Praat acoustic analysis software (Boersma and Weenink, $<$ http://www.fon.hum.uva.nl/praat/>), using phonetic differentiation methods from Ladefoged (2001) and followed analytical criteria used by Grabe and Low (2002).

\section{Results}

I used a normalized Pairwise Variability Index (nPVI) to measure vocalic intervals, vocalic inter-onset intervals, and syllabic inter-onset intervals. Using a series of t-tests, I found no significant difference between English and Korean speakers speaking their native languages or unfamiliar languages (i.e. between English speakers speaking Korean and Korean speakers speaking Korean, between English speakers speaking English and Korean speakers speaking Korean, between Korean speakers speaking English and Korean speakers speaking Korean, etc.) Factors such as language and individual background were eclipsed by the variation between phrases within a single language as pronounced by a single speaker. Patterns of distinctions between individual phrases crossed boundaries of language and nationality. To investigate this intra-language variation, I compared individual syllable lengths across native speakers for each utterance (ex: Figure 2). A one-way ANOVA showed this to be highly significant for all utterances in both English and Korean $(\mathrm{p}<.001)$.

\section{Discussion}

These findings support previous evidence that the Korean language does not neatly fall into any traditional rhythmic category. Lee suggests that the high final to initial syllable ratio of Korean is characteristic of stress-timed languages (1982), while Cho found that in a perception discrimination task in which Korean utterances were reduced to a monotonic series of durations, participants perceived Korean as closest to Japanese, a mora-timed language (2004). Gilleece found vocalic PVI scores of Korean similar to those of British English (2006). Mok and Lee measured vocalic, consonantal, and syllabic variability with similarly mixed results (2008).

The syllabic differentiation found in this experiment demonstrates durational variation in speech similar to stress-timed languages. These variations and resulting perceptual stress patterns play a different role in perception and comprehension of Korean than in English. In Korean, relative syllabic duration and word stress play no lexical function, but may relate to emphasis, syllable weight, phrase pattern, or intonation (Sohn, 1999; Jun, 2005). 


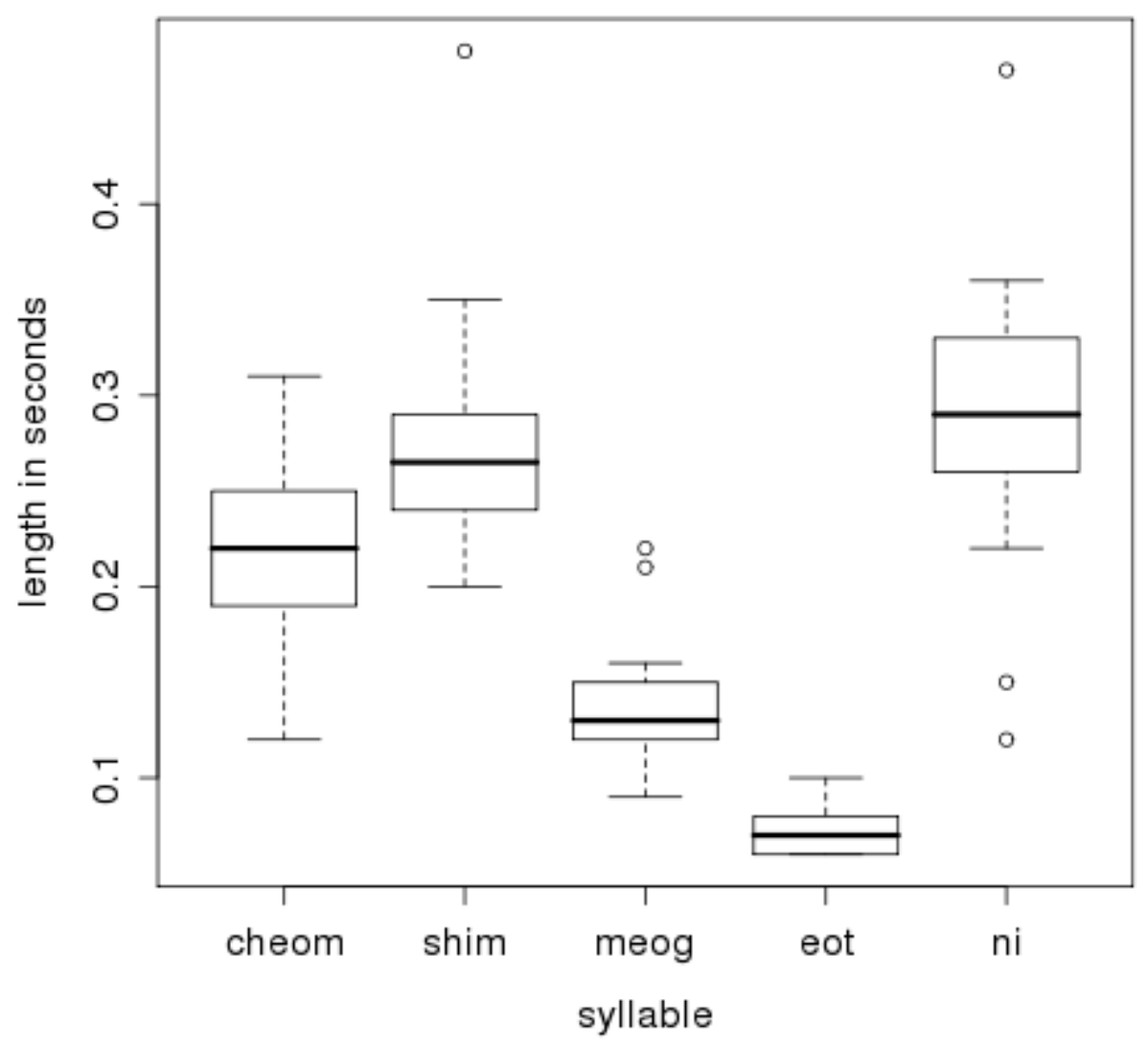

Fig. 2. Korean syllabic durational differentiation in a common utterance

The participants in this experiment speak the Korean of Gyeongsangnamdo province, a dialect which may employ some degree of tonality, a reflection of lexically tonal Middle Korean (Sohn, 1999). This tonality could further influence syllabic variation.

Regardless of the cause, experimental, grammatical, and anecdotal evidence shows that Koreans perceive linguistic rhythm differently from English speakers, though this may not be empirically measurable through recorded utterance in the present experiment. There are several possible reasons for this. Unlike prior studies of this sort (i.e. Patel and Daniele, 2003; Grabe and Low, 2002), this study did not give participants time to practice, and used short familiar utterances rather than long passages. Essentially this study measured a different type of speaking and reading. While the lack of preparation time may have introduced error into the study, the use of short familiar passages may have facilitated the high consistency of syllabic differentiation even in Korean. This implies that while durational variation may not play a lexical role, certain phrases and syllables may be associated with particular prosodic patterns. The relationship between this sort of linguistic rhythm and abstract or musical rhythm is difficult to measure empirically in the present study, but could be addressed using different methods in the future, possibly by focusing on perception rather than production of linguistic phrases (c.f. Iversen et. al., 2008).

\section{TASK 2: CONTINUING SIMPLE RHYTHMIC SEQUENCES}

Previous experiments on Western subjects have shown a tendency to hear and perform durational relationships in simple integer ratios (Collier and Wright, 1995; Essens, 1986; Snyder et al., 2006). Further, in tasks requiring reproduction or spontaneous performance of simple ratios, both musicians and 


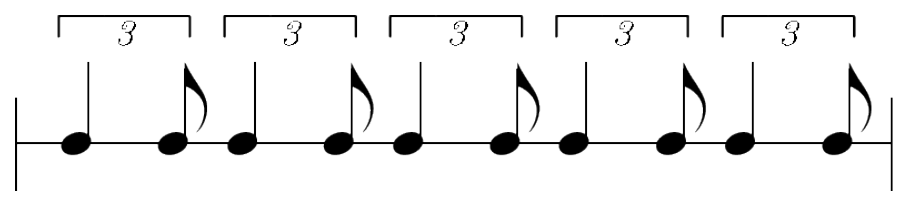

(a) 2:1 duration ratio

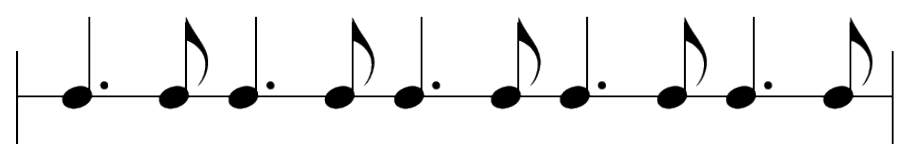

(b) 3:1 duration ratio

Fig. 3. Stimulus patterns in task 2

non-musicians tend towards 2:1 (Povel, 1981; Summers et al., 1986), in many cases performing 2:1 ratios as lower than 2:1 (Gabrielsson, 1987). The following two tasks intend to test whether this abstraction of ratios to a simple long-short relationship is also characteristic of Koreans' perceptions.

\section{Method}

Participants listened to a simple, repetitive rhythmic sequence lasting 5 seconds. They were instructed to clap along with the pattern, and continue clapping after the stimulus finished until told to stop-another 25 seconds. Patterns included equitone sequences of two tones with durations in a 2 to 1 or 3 to 1 ratio (Figure 3). Patterns were presented in a random order at both 60 and 120 beats per minute (bpm), each patterning appearing once at each tempo. All students participated in this task.

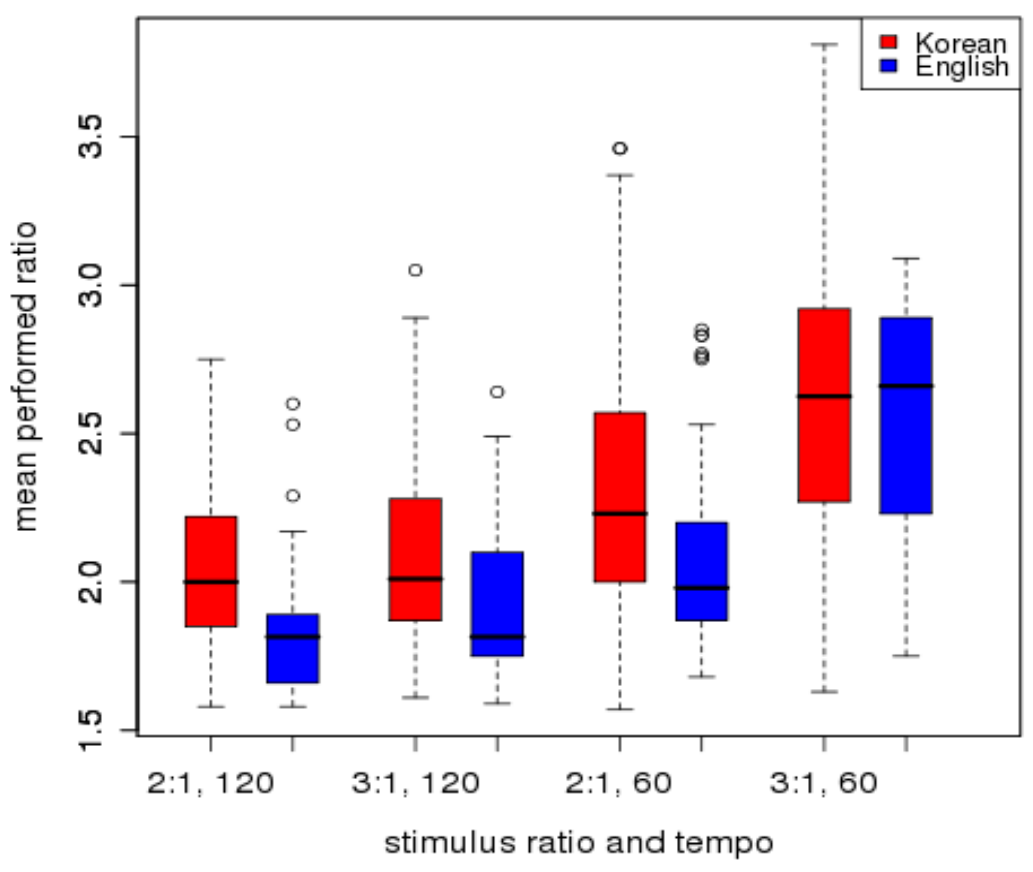

Fig. 4. Korean and English responses to different stimuli by ratio and tempo 


\section{Results}

I analyzed the mean performed ratio of the last five clap pairs of each student (Figure ). A repeated measures mixed effects unbalanced ANOVA showed nationality to be significant $(\mathrm{p}<.005)$ and tempo, ratio, and the interaction between tempo and ratio to be extremely significant $(\mathrm{p}<.0001)$. Koreans consistently performed larger ratios than English, except at slow tempos in response to 3:1 stimulus ratios. At faster tempos both groups showed little distinction between response to 2:1 and 3:1 ratios, with Korean responses approaching 2:1 and English averaging 1.8:1. At slower tempos, both groups performed all ratios as larger and distinguished significantly between 3:1 and 2:1 ratios, with 3:1 performance averaging 2.6:1. This distinction was greater for English than Korean participants. In all cases, 3:1 stimulus ratios elicited more varied response than $2: 1$.

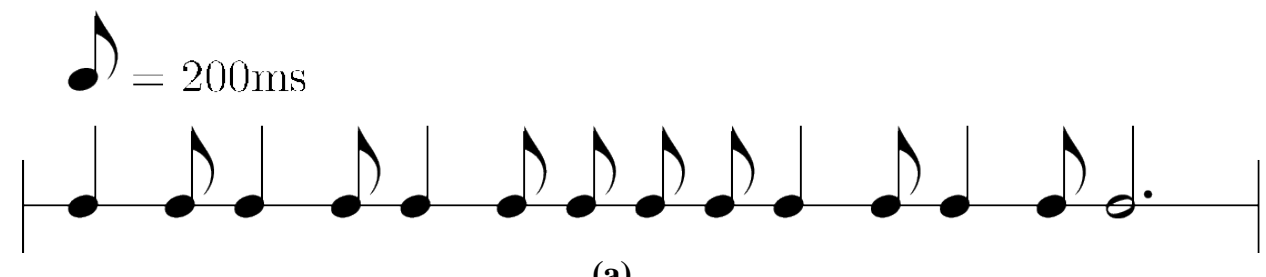

(a)

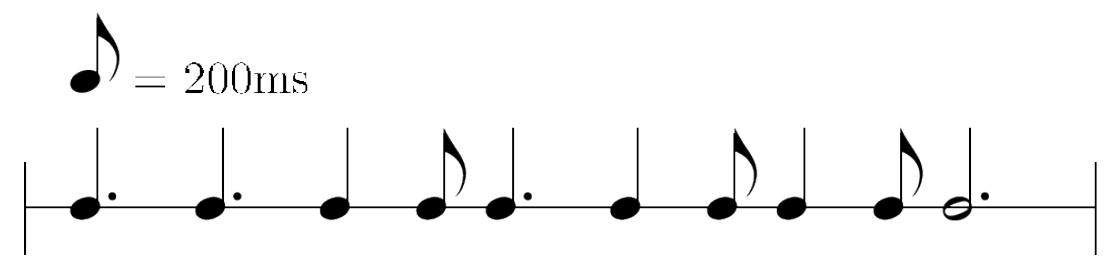

(b)

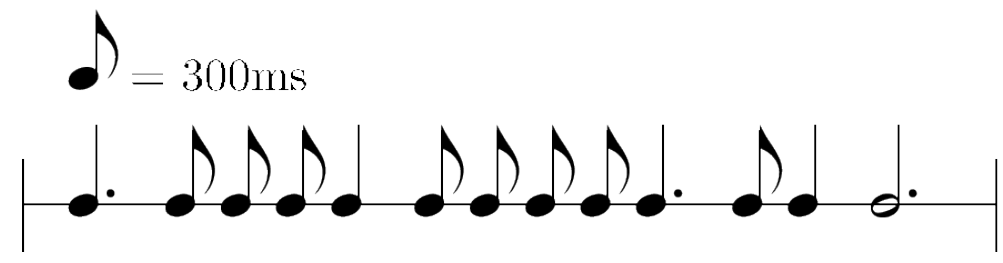

(c)

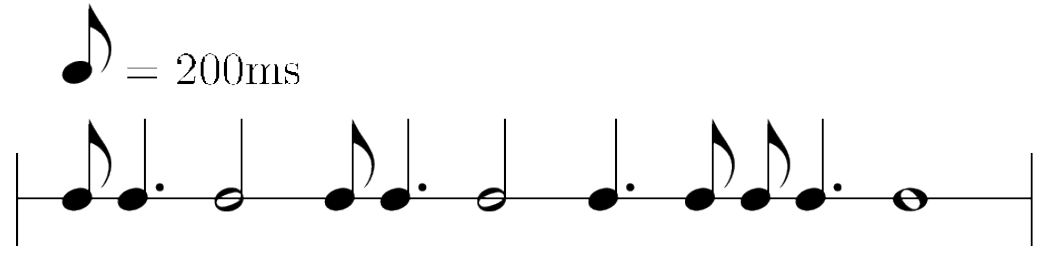

(d)

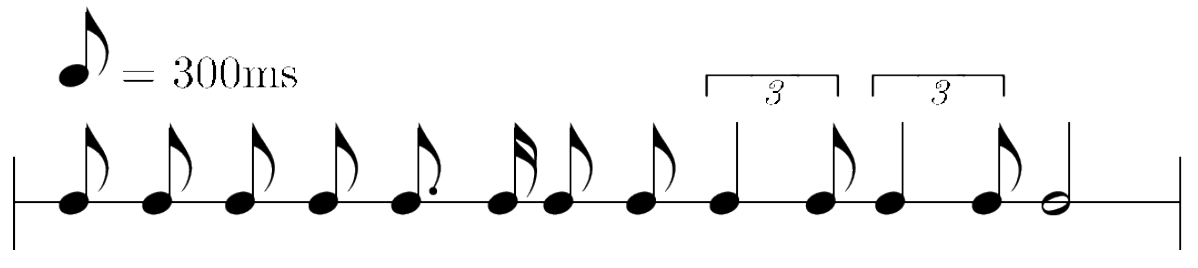

(e)

Fig. 5. Stimulus patterns in task 3 


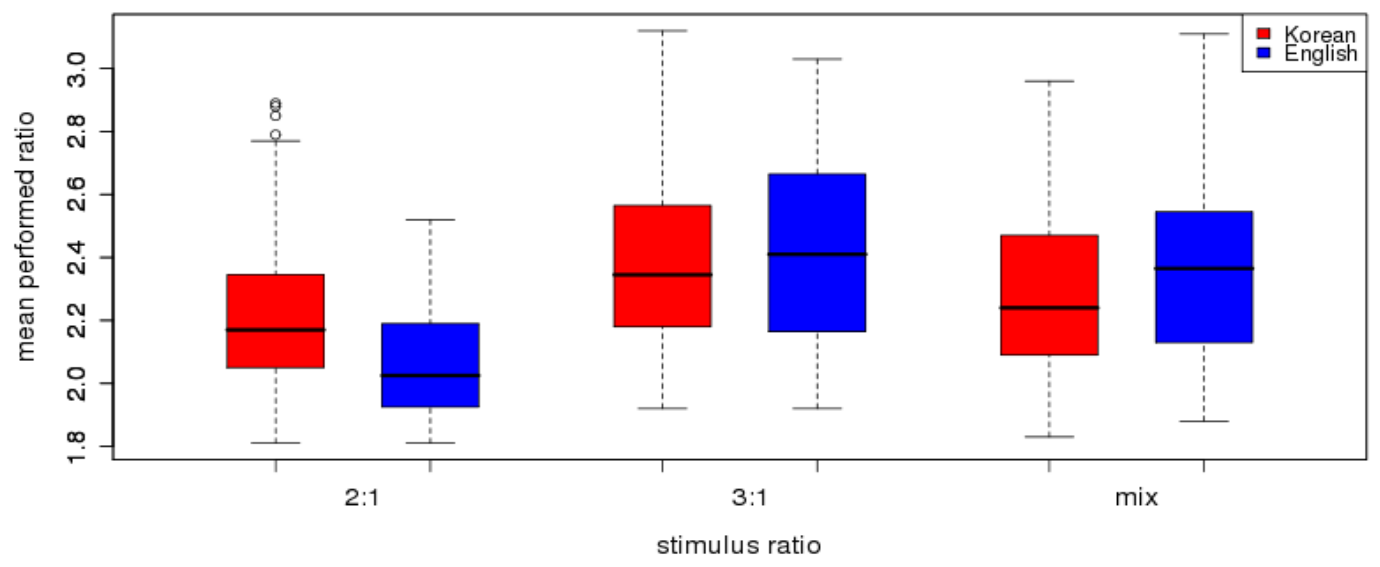

Fig. 6. Korean and English responses to contexts demonstrating 2:1, 3:1, and mixed ratios

\section{TASK 3: REPEATING RHYTHMIC PATTERNS}

\section{Method}

This task tested performance of simple ratios in rhythmic context. Participants listened to a rhythmic pattern lasting no more than 5 seconds (Figure 5). Each pattern appeared once. Participants were instructed to listen and repeat the pattern once. Patterns demonstrated either 2:1 or 3:1 ratios, or a mixture of the two. 109 Korean students and all English and American students took part in this task.

\section{Results}

I analyzed the mean ratio of all clap pairs which fell between 1.8:1 and 3.2:1 (Figure 6). This provided a means of assessing ratio tendencies even where students were unable to accurately reproduce the order of durational relationships in the pattern, while restricting analysis to the perceptual relationship between 2:1 and 3:1 ratios.

Application of a repeated measures mixed effects unbalanced ANOVA showed ratio and the interaction between ratio and nationality to be highly significant $(p<.0001)$. Both Koreans and English respond to all stimuli with ratios significantly smaller than 3:1, with both groups averaging 2.4:1 for the 3:1 ratio. The English group performed smaller ratios in response to the 2:1 stimulus, averaging 1.9:1, which a two-tailed t-test showed to be significant. In response to 3:1 and mixed stimuli, the Korean group performed insignificantly smaller ratios than the English group. As expected, the mixed stimulus elicited responses falling between the other two stimuli, both groups averaging 2.3:1.

\section{TASK 4: CLAPPING THE BEAT}

In the area of Korean traditional music, there is a lack of consistency between published theory and musicians' concepts (Howard, 1991). This is particularly true with regard to meter. Korean music is often transcribed in compound ternary meter, but with different accentual meanings than Western ternary meters would imply. Figure 7 shows two examples of such transcription: chungmori, a rhythmic system commonly transcribed in 12/4, in which accents are placed on the 1st and 9th beats (Pratt, 1987), and Singoyan Taryeong, a folk song found in a standard middle school music textbook in which adjacent bars 


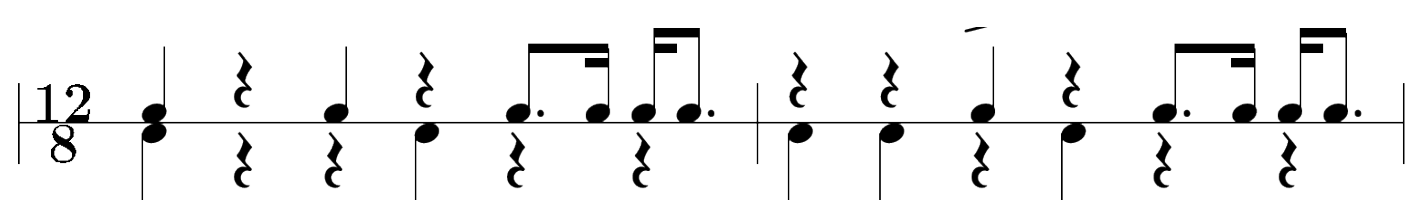

(a) Chungmori; from Pratt (1987)

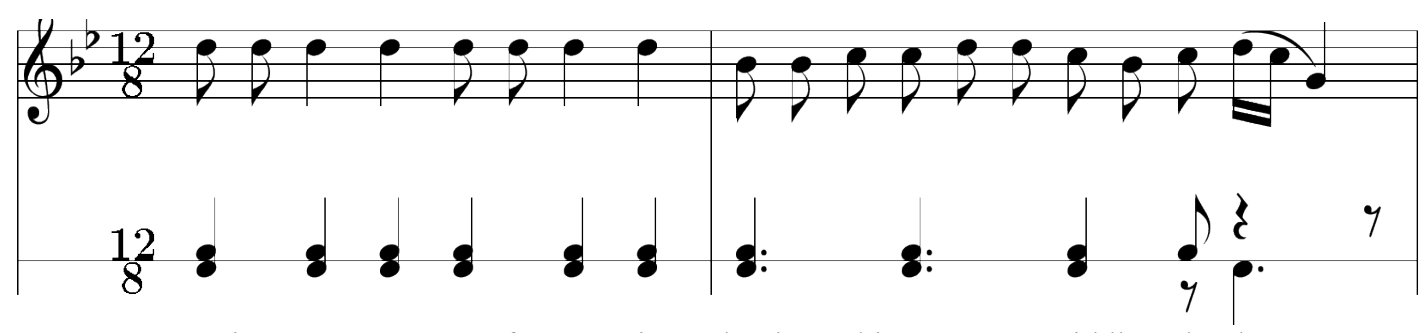

(b) Singoyan Taryeong; from music textbook used in Goseong Middle School

Fig. 7. Metrical discrepancy between Korean traditional music and commonly used Western notation

suggest differing metrical interpretations of a compound time signature. The use of the Western compound ternary meter to transcribe Korean traditional music does not therefore indicate a similarity in perception of such meters. Moreover, traditional Korean music does not employ anacrusis (Pratt, 1987; Howard, 1991), which may also lead to a difference in perceptual tendency. The beat-finding task investigated the ability of Korean and Western participants to find a beat and the tendency to hear rhythms in binary or ternary meters with or without anacrusis.

\section{Method}

Students listened to a rhythmic pattern lasting no more than 5 seconds, repeated for 30 seconds, and were asked to identify and clap the strong beat. Two patterns featured 2-1 rhythmic ratios, two 3-1 rhythmic ratios. All began on a short beat (Figure 8). 44 Korean students took part in this task.

\section{Difficulties and alterations}

Both Korean and English students had difficulty with this test, even when explained in their native language with a demonstration. Most students tried to clap the pattern exactly. Some clapped every beat or did not clap at all, and still others clapped an isochronous series which did not relate to the pattern. For this reason, I expanded the test to include three patterns from Test 3, 5(a), 5(b), and 5(d), one of which, 5(d), was repeated twice. Both 5(a) and 5(b) begin with a long duration. This addition allowed the students more practice with easier patterns, which facilitated understanding of the task. A further 24 Korean students, as well as all English and American students took part in this altered version of the task.

\section{Results}

I used mixed effect repeated measures unbalanced ANOVAs to examine significant factors in competence of performing this task, metrical interpretation, and perception of anacrusis. Analysis of competence and anacrusis includes only results of the expanded version of the task; analysis of metrical interpretation also includes results from the first version. 


\section{COMPETENCE}

I considered responses competent beat decisions if they were consistent and isochronous relative to the stimulus. I discounted responses which indicated a different beat choice on more than 3 subsequent repetitions as well as those which displayed durational ratios exceeding 1.3:1. In analyzing factors in determining competence, I refer to a competence index, indicating the proportion of students from each group able to identify a consistent and isochronous beat according to these criteria.

In the expanded version of the test, participants were significantly $(p<.05)$ more competent at patterns beginning with a long duration (Figure 9). Among these participants nationality was significant (p $<.05)$ and tempo was extremely significant $(\mathrm{p}<.0005)$ in determining competence at this task (Figure 10$)$. All participants were significantly more competent at faster speeds, and Koreans were consistently less competent and more varied in response that the English group, possibly owing to experimental constraints as discussed above.

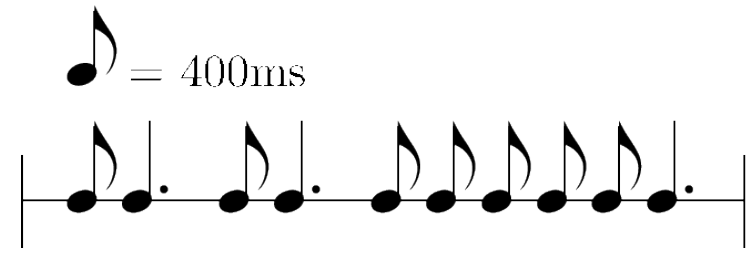

(a)

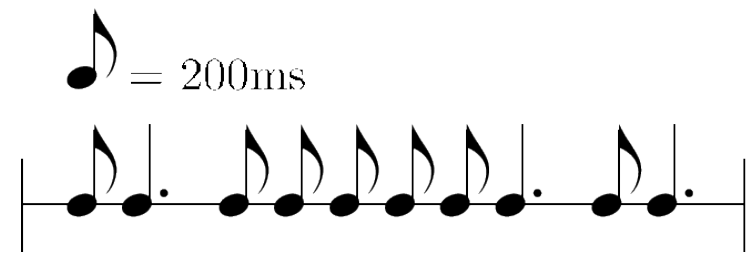

(b)

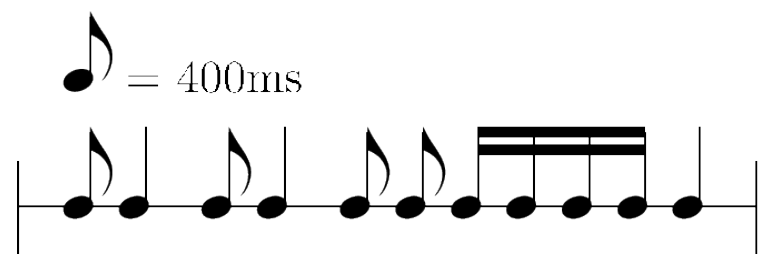

(c)

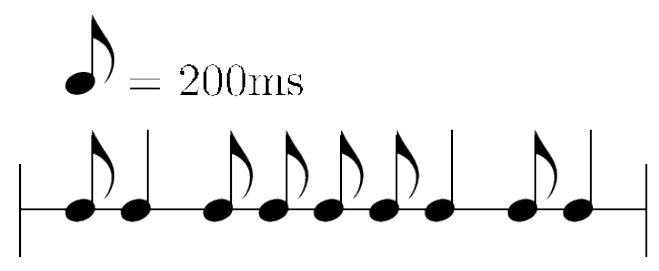

(d)

Fig. 8. Stimulus patterns in task 4 


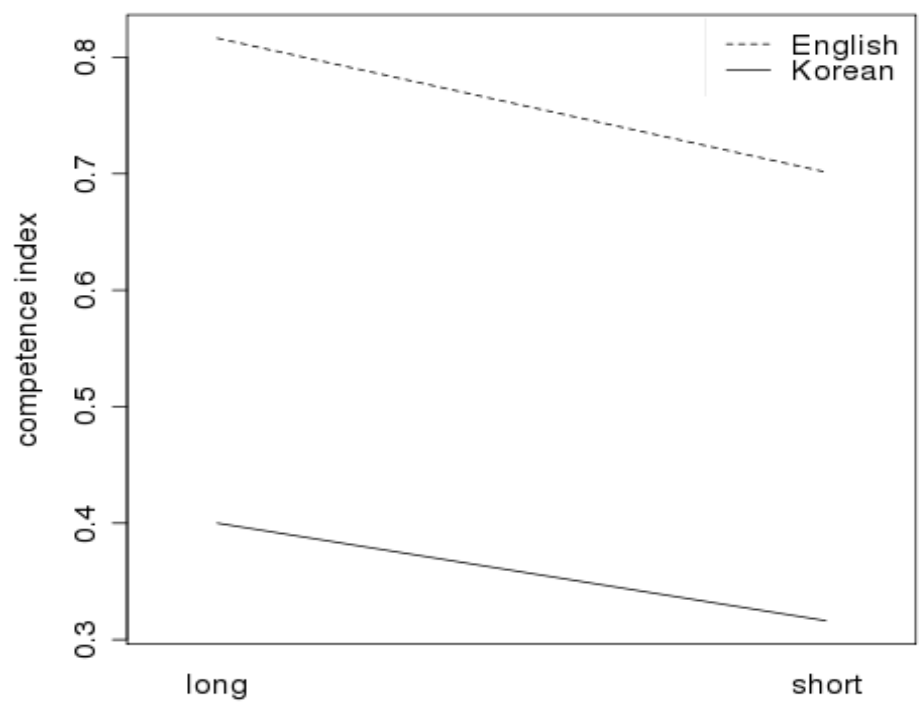

Fig. 9. Ability to clap an isochronous beat in response to stimuli beginning on long or short beats

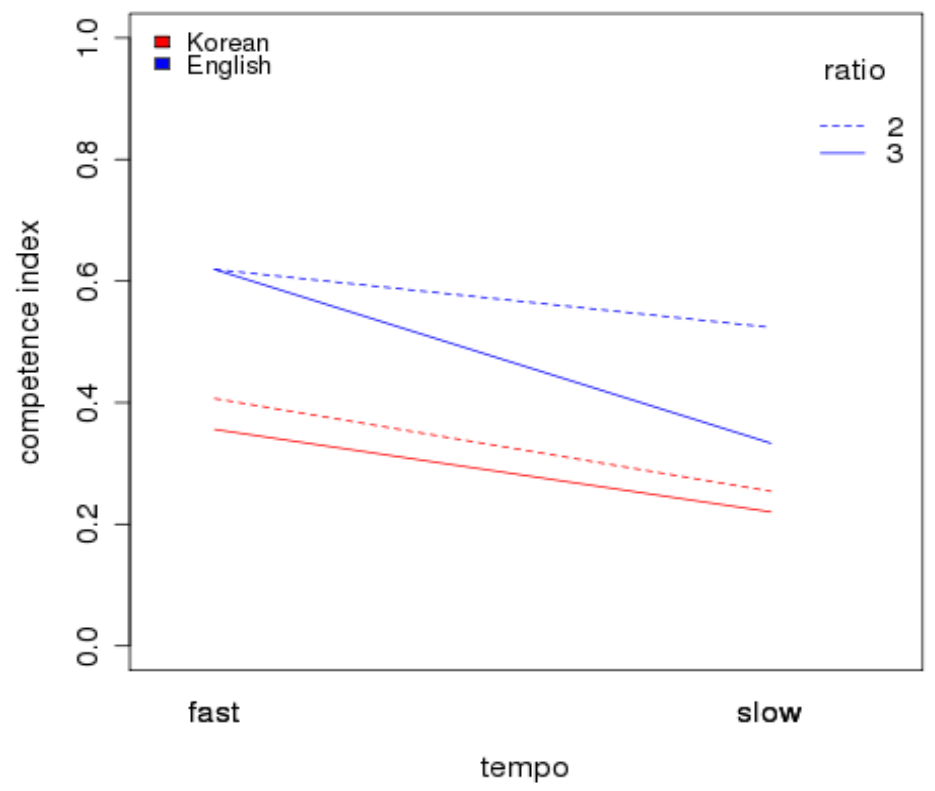

Fig. 10. Ability to clap an isochronous beat in response to stimuli of different tempi and ratios 


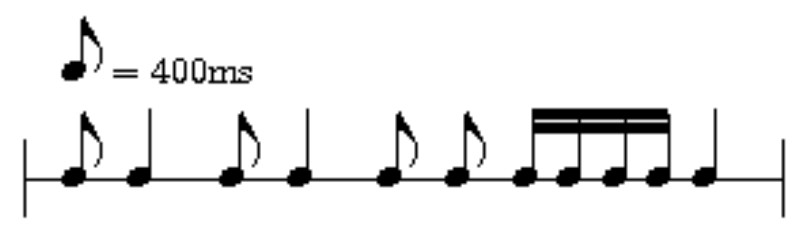

(s) stirrulus

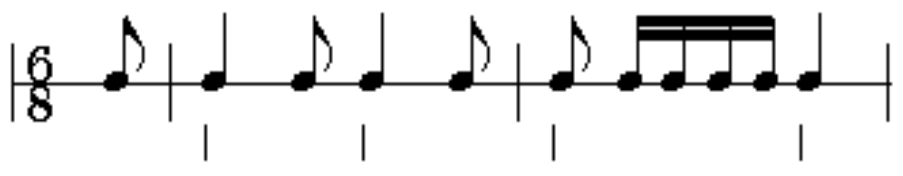

(b) compound with snsartusis

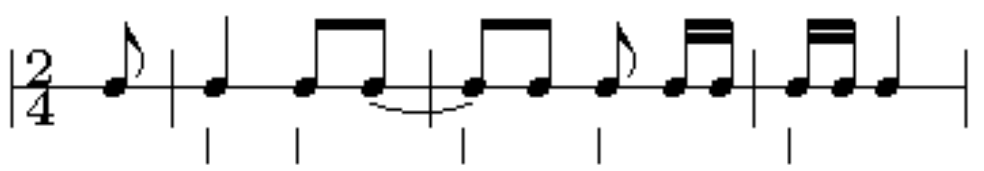

(c) simple binary with snsurtusis

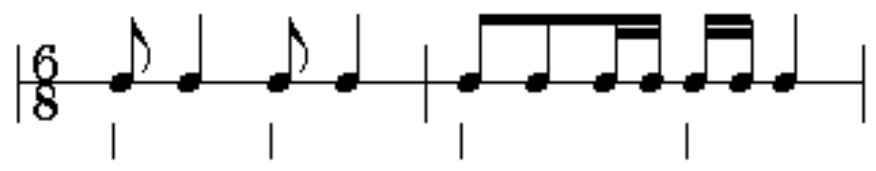

(d) compound without snsurusis

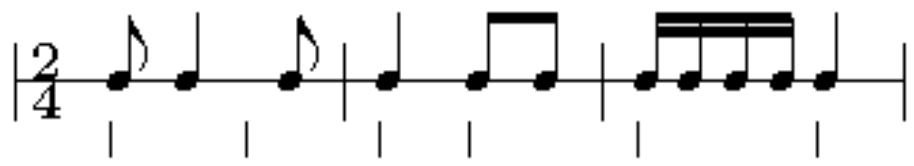

(e) simple binsry without snsuruzis

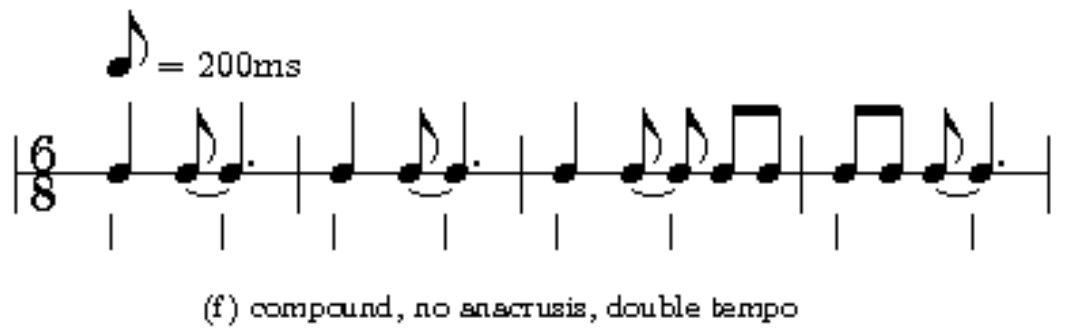

Fig. 11. Metrical interpretations of pattern 8(c); lines indicate clapped beats 


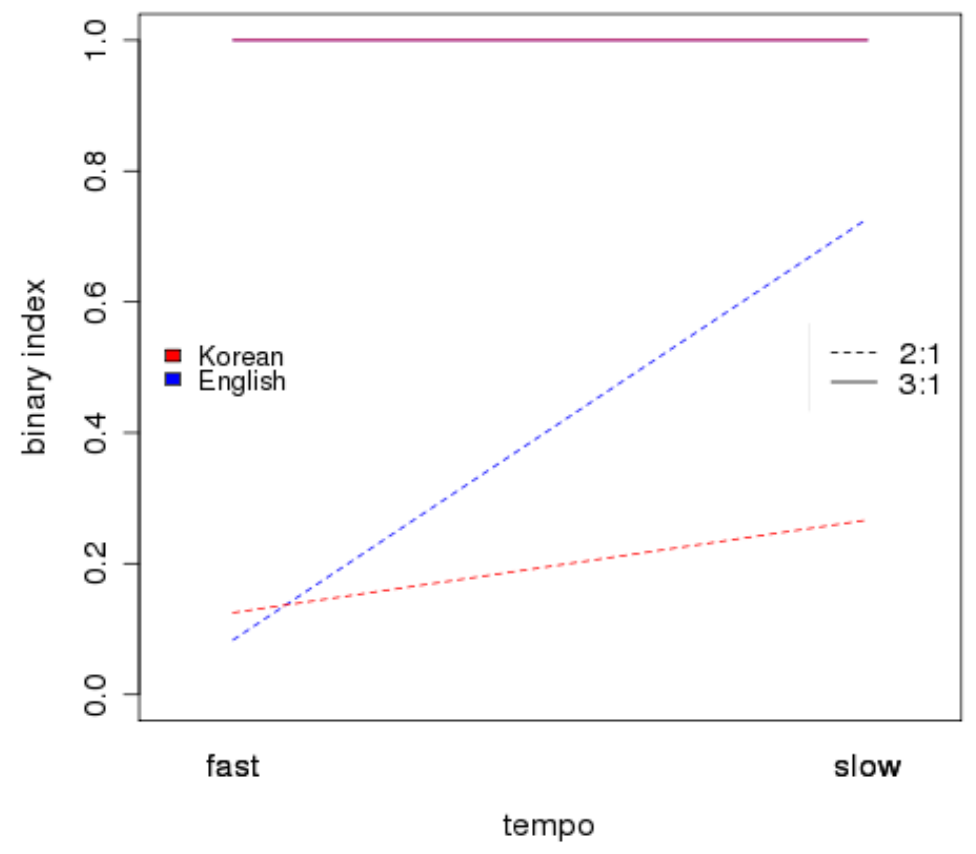

Fig. 12. Tendency to hear patterns in simple binary meters by tempo, ratio, and nationality

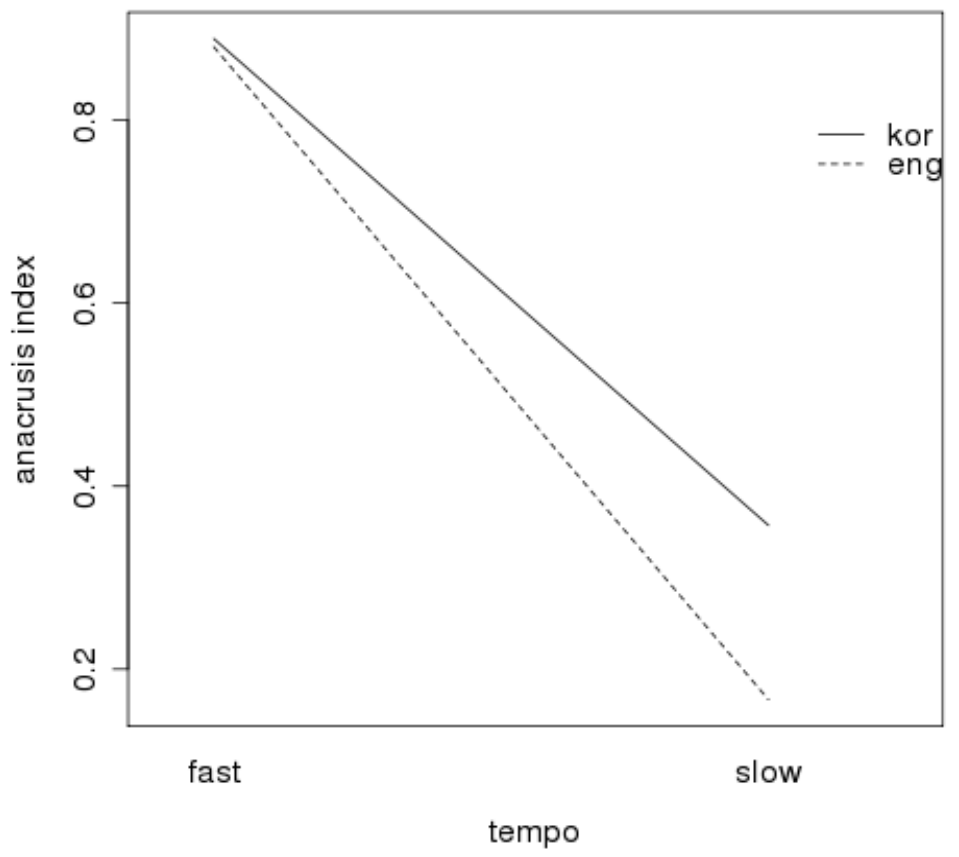

Fig. 13. Tendency to hear anacrusis by tempo and nationality 


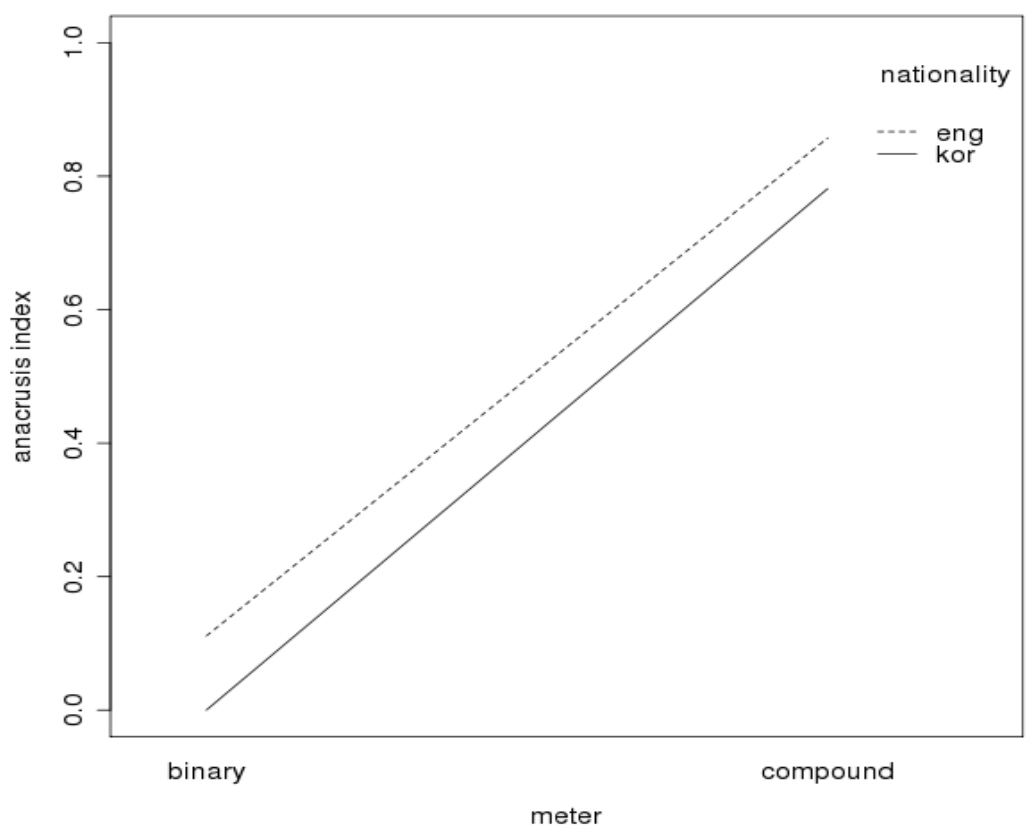

Fig. 14. Relationship between anacrusis and meter in response to stimuli with $2: 1$ duration ratios

\section{METRICAL INTERPRETATION}

Student responses showed a wide variety of metrical interpretations of the stimuli. Figure 11 shows the range of responses to stimulus $8(\mathrm{c})$. There was one example of a ternary response to stimulus $8(\mathrm{~d})$; otherwise all interpretations were either simple binary or compound. In analysis I refer to a binary index, meaning the proportion of responses from each group demonstrating a simple binary interpretation, as opposed to a compound interpretation.

Significant factors in the choice of simple binary or compound metrical interpretation were primary stimulus ratio $(\mathrm{p}<.0001)$, tempo $(\mathrm{p}<.0001)$, and the interactions between nationality and tempo $(\mathrm{p}<.001)$, ratio and tempo $(\mathrm{p}<.0005)$, and nationality, ratio, and tempo $(\mathrm{p}<.02)$ (Figure 12). Participants heard stimuli demonstrating 3:1 ratios in simple binary meters. For stimuli demonstrating 2:1 ratios, metrical interpretation was related to tempo. At faster tempos (shortest $\mathrm{IOI}=200 \mathrm{~ms}$ ), more participants showed a compound interpretation, while at slower tempos more participants heard simple binary metrical structures. These effects were more pronounced among participants in the English group.

\section{ANACRUSIS}

I discuss an anacrusis index as the proportion of responses in a group indicating an anacrustic interpretation. Stimulus tempo $(\mathrm{p}<.0001)$, metrical interpretation $(\mathrm{p}<.0001)$, and the interactions between tempo and metrical interpretation $(\mathrm{p}<.005)$ were significant in relation to perception of anacrusis (Figure 13). Nationality was not significant. For both groups, perception of anacrusis was significantly more common at faster tempos. For 2:1 stimuli, meter relates to anacrusis at all tempos (Figure 14): with one exception (11(c)), simple binary metrical interpretations did not include anacruses.

\section{Discussion}

The relationship between tempo and anacrusis perception relates to a prior study by London, Himberg, and Cross (2006) which likewise showed that anacrusis perception is more likely at faster tempos among 
Western listeners. One possible reason for this may be the tendency to align perceptual tactus with a standard reference tempo, approximately $600 \mathrm{~ms}$ per event, with the lower threshold for tactus perception of approximately $250 \mathrm{~ms}$ per event. For stimuli in which the relatively short initial event duration is 200 $\mathrm{ms}$, this event is likely to be heard as a fraction of the beat, rather the beat itself, encouraging an anacrustic interpretation.

Moreover, these tempo tendencies may influence overall metrical interpretation. At slower stimulus tempos, short events are more likely to be heard as the tactus. While for stimuli employing 3:1 ratios, this results in a simple binary metrical structure, for stimuli employing 2:1 ratios, this results in a ternary metrical structure. In this experiment, participants preferred interpretations employing a syncopated binary structure to such ternary interpretations. At faster tempi, compound interpretations of stimuli employing a 2:1 ratio maintain a binary tactus. Both groups showed this tendency to binary, though Koreans to a lesser extent.

Previous neurological and perceptual studies have suggested innate preference for binary metric structure, or an internal binary default schema in Western listeners (Smith and Cuddy, 1989; Brochard et al., 2003; Desain and H.Honig, 2003; Abecasis et al., 2005). This idea has hitherto lacked cross-cultural empirical support.

\section{QUESTIONNAIRE RESPONSES}

470 Korean students and 20 teachers filled out a questionnaire on listening and performance experience. All aspects of the questionnaire were translated and explained with relevant examples.

Students reported frequency of listening to different types of music in terms of once a day, once a week, once a month, or once a year, which I translated into a four point scale ( $1=$ once a year, $4=$ once a day) and averaged across participants. Korean Middle school students showed a significant preference for Korean popular music (avg. score $=3.4$ ), which strongly resembles Western popular music, over all other types of music. Western popular music itself scored higher (2.27) than both Korean traditional music and Western classical music. There was no significant difference between reported time spent listening to Western classical music (1.88) and time spent listening to Korean traditional music (1.9), though there was a slight difference between city schools and country schools, with students at country schools reporting slightly more time spent listening to Korean traditional music (2.15) than students at city schools (1.85).

The responses further included 322 instances of students playing Western instruments, and 52 instances of students playing Korean traditional instruments. School curriculums strongly emphasize Western music over Korean traditional music, with in-class lessons in recorder and extra-curricular band activities. Some schools also have extra-curricular traditional music ensembles, particularly samulnori groups. Students do not generally learn Korean traditional notation systems.

Overall the questionnaire responses show the prominence of Western music and Western musical systems in South Korea.

\section{GENERAL DISCUSSION AND CONCLUSION}

The results of the three clapping tasks suggest that different perceptual schema may be operating at different tempos. As a subdivision of the beat, listeners prefer small integer ratios, while in terms of meter, listeners prefer binary metrical structures with the tactus IOI approaching 600ms.

At faster speeds, participant responses show that the underlying beat is more salient while the distinction between ratios is less salient. Previous investigations of ratio perception as a function of tempo have shown that distortion of duration ratios increases at faster tempos (Repp et al., 2005) and that at fast tempos performed ratio can be well below target ratio (Collier and Wright, 1995). This interval distortion may relate to the beat discrimination threshold of $100 \mathrm{~ms}$. In the $120 \mathrm{bpm}$ equitone sequences employed in this experiment, the short duration has an IOI of $166 \mathrm{~ms}$ for $2: 1$ and $125 \mathrm{~ms}$ for $3: 1$ stimuli. As this duration approaches $100 \mathrm{~ms}$, participants may find it harder to accurately replicate, instead shortening the longer duration to maintain the beat IOI, as represented by the total of the ratio pair (see also Repp et al., 2002). In the context-based clapping task, where the shortest event IOI only approaches $200 \mathrm{~ms}$, the reduction of the 2:1 ratio is not significant. Thus at faster tempos, where the 2:1 and 3:1 event pairs are heard as components of the beat, distinction between duration ratios may be less salient than the perceived beat. At slower tempos, where components of interval ratios may be interpreted as tactus, metrical factors may 
interact with specific ratio considerations. Summers et al. demonstrated that in rhythmic imitation tasks, participants altered durational ratios to conform to metric interpretations (1986).

Differences between the Korean and English group were largely a matter of degree rather than direction of these tendencies. It is difficult to judge whether this variation is due to language or cultural differences, or to different experimental conditions and interpretations.

The similarities are likewise problematic to interpret. While the tendency of all participants to reduce 3:1 ratios to approach 2:1 and to hear anacrusis at faster tempos may suggest that these effects are not specific to Western culture, it may equally indicate the high degree of Western musical enculturation in modern South Korea.

While the study of linguistic rhythm proved inconclusive within the scope of the study, it did raise wider considerations regarding prosodic consistency in familiar phrases, even in languages in which durational accent plays no lexical role. This merits further research in languages which previous studies have more definitely classified, such as Japanese.

Overall this study has provided some evidence of similar rhythmic perceptual tendencies in Korean and Western students which could be usefully compounded through similar studies in different cultural regions. The simplicity and flexibility of the experimental setup facilitate such use in future crosscultural musical research.

\section{REFERENCES}

Abecasis, D., Brochard, R., Granot, R., \& Drake, C. (2005). Differential brain response to metrical accents in isochronous auditory sequences. Music Perception, Vol. 22, No. 3.

Beckman, M.E. (1992). Evidence for speech rhythms across languages. In: Tohkura, Y., VatikiotisBateson, \& Sagisaka, Y., editors, Speech Perception, Production and Linguistic Structure. IOS Press.

Brochard, R., Abecasis, D., Potter, D., Ragot, R., \& Drake, C. (2003). The ticktock of our internal clock: direct brain evidence of subjective accents in isochronous sequences. Psychological Science, Vol. 14, No. 4.

Cho, M.-H. (2004). Rhythmic Typology of Korean Speech. Cognitive Processing 5, 2004.

Cole, M. (1996). Cultural Psychology: A Once and Future Discipline. Belknap Press of Harvard University Press, Cambridge, Massachusetts.

Collier, G. L. \& Wright, C. E. (1995). Temporal rescaling of simple and complex ratios in rhythmic tapping. Journal of Experimental Psychology: Human Perception and Performance, Vol. 21, No. 3.

Dauer, R. (1983). Stress-timing and syllable timing reanalysed. Journal of Phonetics, 11.

Desain, P. \& H.Honig (2003). The formation of rhythmic categories and metric priming. Perception, Vol. 32, No. 3 .

Drake, C. (1993). Reproduction of musical rhythms by children, adult musicians, and adult nonmusicians. Perception and Psychophysics, Vol. 53, No. 1.

Essens (1986). Hierarchical organization of temporal patterns. Perception and Psychophysics, Vol. 40, No. 2.

Gabrielsson, A. (1987). Once again: The theme from Mozart's piano sonata in A Major (K. 331). In: Gabrielsson, A., (Ed.), Action and perception in rhythm and music, number 55. Royal Swedish Academy of Music, Stockholm.

Gilleece, L. F. (2006). An Empirical Investigation of the Association between Musical Aptitude and Foreign Language Aptitude. PhD Thesis, Trinity College, Dublin. 
Grabe, E. \& Low, E. L. (2002). Durational variability in speech and the rhythm class hypothesis. In: Papers in Laboratory Phonology 7, Mouton.

Howard, K. (1991). Why do it that way? Rhythmic models and motifs in Korean percussion bands. Asian Music, Vol. 23, No. 1.

Huron, D. \& Ollen, J. (2003). Agogic contrast in French and English themes: Further support for Patel and Daniele. Music Perception, Vol. 21.

Iversen, JR, Patel AD, and Ohgushi, K. (2008) Perception of rhythmic grouping depends on auditory experience. Journal of the Acoustical Society of America.

Jun, S.-A. (2005). Prosodic Typology: The Phonology of Intonation and Phrasing. Oxford University Press, Oxford.

Ladefoged, P. (2001). Vowels and Consonants: An Introduction to the Sounds of Languages. Blackwell Publications.

Lee, H. B. (1982). A phonetic study of rhythm in standard Korean. Malsori, Vol. 4.

London, J., Cross, I., \& Himberg, T. (2006). The effect of tempo on the perception of anacruses. In: Proceedings of the 9th International Conference on Music Perception and Cognition.

Louhivuori, J. (2002). Cross-cultural approach in music perception and cognition. In: Proceedings of the 7th International Conference on Music Perception and Cognition.

Mok, P. and Lee, S. I. (2008). Korean speech rhythm using rhythmic measures. In: The $18^{\text {th }}$ International Congress of Linguists.

Ohgushi, K. (2002). Comparison of dotted rhythm expression between Japanese and Western pianists. In: Proceedings of the 7th International Conference on Music Perception and Cognition.

Parncutt, R. (1994). A perceptual model of pulse salience and metrical accent in musical rhythms. Music Perception, Vol. 11.

Patel, A. D. \& Daniele, J. R. (2003). An empirical comparison of rhythm in language and music. Cognition, Vol. 87.

Patel, A. D., Iversen, J. R., \& Rosenberg, J. C. (2006). Comparing the rhythm and melody of speech and music: The case of British English and French. Journal of the Acoustical Society of America, Vol. 119.

Povel, D. J. (1981). Internal representation of simple temporal patterns. Journal of Experimental Psychology: Human Perception and Performance, Vol. 7, No. 1.

Pratt, K. (1987). Korean music: its history and its performance. Faber Music.

Ramus, F. (2002). Acoustic correlates of linguistic rhythm: Perspectives. In: Proceedings of Speech Prosody.

Repp, B. H., London, J., \& Keller, P. E. (2005). Production and synchronization of uneven rhythms at fast tempi. Music Perception, Vol. 23, No. 1.

Repp, B. H., Windsor, W. L., \& Desain, P. (2002). Effects of tempo on the timing of simple musical rhythms. Music Perception, Vol. 19, No. 4. 
Sadakata, M., Ohgushi, K., \& Desain, P. (2004). A cross-cultural comparison study of the production of simple rhythmic patterns. Psychology of Music, Vol. 32, No. 4.

Smith, K. C. \& Cuddy, C. L. (1989). Effects of metric and harmonic rhythm on the detection of pitch alterations in melodic sequences. Journal of Experimental Psychology: Human Perception and Performance, Vol. 15.

Snyder, J. S., Hannon, E. E., Large, E. W., \& Christiansen, M. H. (2006). Synchronization and continuation tapping to complex meters. Music Perception, Vol. 24, No. 2.

Sohn, H.-M. (1999). The Korean Language. Cambridge University Press.

Summers, J. J., Hawkins, S. R., \& Mayers, H. (1986). Imitation and production of interval ratios. Perception and Psychophysics, Vol. 39, No. 6. 